\title{
Breast cancer in Rivers State, Nigeria: Ten-year review of the Port Harcourt cancer registry
}

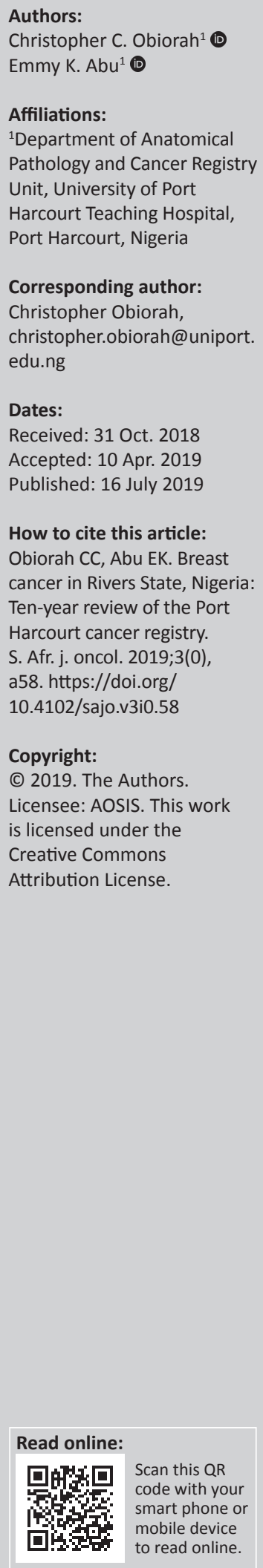

Background: With breast cancer (BCA) causing high morbidity and mortality among Nigerians, no population-based cancer registry study has been carried out in Rivers State.

Aim: The aim of this study was to provide population-based BCA profile in Port Harcourt and environs.

Setting: Port Harcourt cancer registry situated at the University of Port Harcourt Teaching Hospital, Rivers State, Nigeria.

Method: Port Harcourt cancer registry data were reviewed for BCAs recorded between 2008 and 2017. Trend analysis and Minitab version 16 software were used to forecast incidence.

Results: Breast cancers with 777 cases (29\%) constituted the commonest cancer among both males and females: $49.7 \%$ and $3 \%$ of all female and male cancers, respectively. Female to male ratio was 20.6:1. While the age range was 15-98 years, the mean age was 45.9 (12.6) years (95\% confidence interval [CI], 45.0-46.7). The combined peak age group was 40-44 years. The mean age of the females was 45.5 (12.4) years (95\% CI, 44.6-46.4), while that of the males was 53.5 (13.7) years (95\% CI, 48.9-58.1). Diagnosis was significantly associated with gender $(p<0.05)$. Although 48 cases $(6.2 \%)$ were below 30 years and 454 cases $(58.4 \%)$ were between 30 and 49 years, diagnosis was not significantly associated with age $(p>0.05)$. Age-adjusted rate ranged between 3.9/100 000 in 2008 and 19.7/100 000 in 2017. Infiltrating ductal carcinomas constituted 97.9\%. In situ carcinomas constituted $0.7 \%$. Infiltrating lobular carcinoma constituted $1.4 \%$. Malignant stromal tumours constituted $0.6 \%$.

Conclusion: The burden of BCA is heavy in Port Harcourt, and the mean age is lower than the figures of developed nations. Instituting measures that will entrench prevention, screening, timely diagnosis and improved treatment is imperative.

Keywords: population; cancer; registry; breast; morphology; Port Harcourt.

\section{Introduction}

Breast cancer (BCA) is currently the most common cancer worldwide, having increased from 1.7 million cases in 2005 to 2.4 million cases in $2015 .{ }^{1}$ It constitutes a major public health issue, with over 1 million new cases diagnosed annually - posing a serious threat to the health of women of all races globally. Although it is the most common cancer in women, it also causes significant morbidity and mortality among men. There is regional variation in the incidence of BCA, with the Western countries having a significantly higher proportion than the African and Asian population. East Asian women have the lowest incidence rate (21/100 000), compared with 101/100 000 in the United States and 85/100 000 in Western Europe. ${ }^{2}$ Within Africa, there is regional variation in incidence, with reports showing that $27 \%$ of BCAs occurred among the North African countries (Algeria and Egypt) compared with 15\% that was reported in subSaharan Africa. ${ }^{3}$ Also, GLOBOCAN 2012 reports estimated that the incidence of BCA ranged from 27/100 000 women in central Africa to 39/100 000 women in southern Africa, while that of China was 25.9/100 000 and Greece was 43.9/100 000., ${ }^{45}$ However, currently there is general increase in BCA in Africa because of 'Westernised lifestyle' and better reporting with a projected doubling of the burden by 2030. The projected increase is because of ageing, population growth, adoption of unhealthy lifestyles and the absence of effective public health policies and interventions against BCA. 6,7 Late presentation, advanced stages of disease at diagnosis, poor healthcare infrastructure, lack of adequate funding, non-affordability of the available services by most patients, superstition and low awareness of the disease leave the average Nigerian patient with poor prognosis and survival. $5,8,9,10$ 
There is inadequate epidemiologic risk factor data and information on BCA among African nations including Nigeria, and this is partly responsible for the restricted evidence-based interventions and the limited prevention and control programmes. ${ }^{11}$ Therefore, local domiciliation of BCA research programmes is imperative considering the disparity in BCA incidence even among the geopolitical zones of Nigeria, coupled with the need to optimise utility of scarce resources through guided and priority-driven allocation. There has not been any population-based BCA study in Rivers State. Port Harcourt and Obio-Akpor, being the statutory capital of Rivers State - the epicentre of the oil-rich Niger Delta region of Nigeria and the attendant cosmopolitan settlement - deserves to have articulated and documented profile of BCA.

It is hoped that this first population-based cancer registry work on BCA in Port Harcourt and the environs will provide a framework for further epidemiologic cancer-related research activities in our locality.

\section{Methodology}

The data for this work were obtained from the Port Harcourt cancer registry (PHCR), located at the University of Port Harcourt Teaching Hospital (UPTH). Port Harcourt cancer registry operates as a population-based registry covering Port Harcourt city and Obio-Akpor local government areas with joint population in 2006 census of 1000908 (19.3\% of Rivers State population). The two local government areas together constitute the capital of Rivers State - hosting the seat of government and maintaining the nucleus of specialised medical care in the state. Officials of the National Population Commission made the annual population projection for 2008-2017 from the 2006 census figures. Generally, in PHCR, active data collection is employed as registry personnel visit notification centres to obtain relevant information on cancer patients. Cases are defined and verified by histology, cytology and haematology smear reports as well as patients' physical examination findings, clinical impressions and autopsy reports or death certificate reviews. Thus, cases diagnosed through clinical impressions or laboratory investigations were registered. Notification sources include outpatients' departments and wards of the tertiary, general and private hospitals; pathology and radiology centres involved in the diagnosis and treatment of cancer within the catchment areas; and UPTH mortuary. Identified cases were classified and coded, using the International Classification of Disease for Oncology, 3rd edition (ICD-O3), ${ }^{12}$ while the storage, duplicity-checking and processing of data were achieved with the use of CanReg 4 software. As much as possible, completeness of case registration devoid of duplication was ensured, through regular visits to the notification sources and performance of duplication checks. Cases without age and those with ill-defined diagnoses were excluded from analysis. Data on the dates of incidence, gender, age, topography, morphology of the lesion and degree of differentiation were retrieved. Obtained data were exported to SPSS version 23 for analysis. The age-specific rates (ASRs) per 100000 of the population and age-adjusted rates (AARs) per 100000 were calculated using World Health Organization (WHO) world standard population figures. ${ }^{13}$ Pearson's chi-square test $p<0.05$ was taken to be statistically significant.

\section{Ethical considerations}

Ethical clearance was obtained from the Research Ethics Committee of the University of Port Harcourt Teaching Hospital, reference number: UPTH/ADM/90/S.II/VOL. $\mathrm{XI} / 714$.

\section{Results}

Of the 2682 cancers recorded in the registry within the 10 -year period, BCA constituted 777 cases (29\%) and the most frequently diagnosed cancer in males and females combined. Among females, it constituted $49.7 \%$ of all malignancies, while in the males it constituted 3\% of all malignancies. There were 741 females and 36 males, giving a female to male ratio of 20.6:1

The overall age range and mean age were 15-98 years and $45.9 \pm 12.6$ years (95\% confidence interval [CI], 45.0-46.7), while the overall peak age group was $40-44$ years with $128 / 777$ cases $(16.6 \%)$. The peak age group among females only was $40-44$ years with $123 / 741$ cases $(16.6 \%)$, while among males it was 65-69 years with $9 / 36$ cases (25\%) (see Figure 1 ).

The mean age of the females was $45.5 \pm 12.4$ years $(95 \% \mathrm{CI}$, 44.6-46.4), while that of the males was $53.5 \pm 13.7$ years $(95 \%$ CI, 48.9-58.1). In both males and females, the incidence rate increased with age up to the respective peaks.

For males and females combined, the ASR ranged between 0.78/100 000 for 15-19 age group and 455/100 000 for 65-69 years, while the AAR ranged between $0.07 / 100000$ for 15-19 years and 14.4/100 000 for 60-64 years. For females only, the ASR ranged between 1.49 and 932/100 000 for the 15-19 and 60-64 years age groups, respectively, while the AAR ranged between 0.13 and 35.03/100 000 for the 15-19 and 55-59 age groups, respectively. For males, the ASR ranged between 1.15 and 191.13/100 000 for those aged between 20-24 and 65-69 years, respectively, while the AAR ranged between 0.09 and 5.66/100 000 for the 20-24 and 65-69 years age groups, respectively. The overall annual ASR ranged between 98.2 in 2008 and 479/100 000 in 2017, while the overall annual AAR ranged between 3.9/100 000 in 2008 and 19.7/100 000 in 2017 (Tables 1 and 2).

The annual frequency trend is undulating, but overall depicts increase in number of cases from 21 cases recorded in 2008 to 153 cases in 2017 (see Figure 2).

The majority of the cases were ductal carcinomas $-761 / 777$ cases $(97.9 \%)$, of which only 5 cases $(0.7 \%)$ were non-invasive in situ carcinomas. Of the invasive 756 cases (97.3\%), 694 cases (89.3\%) were not otherwise specified (NOS), while 62 cases 


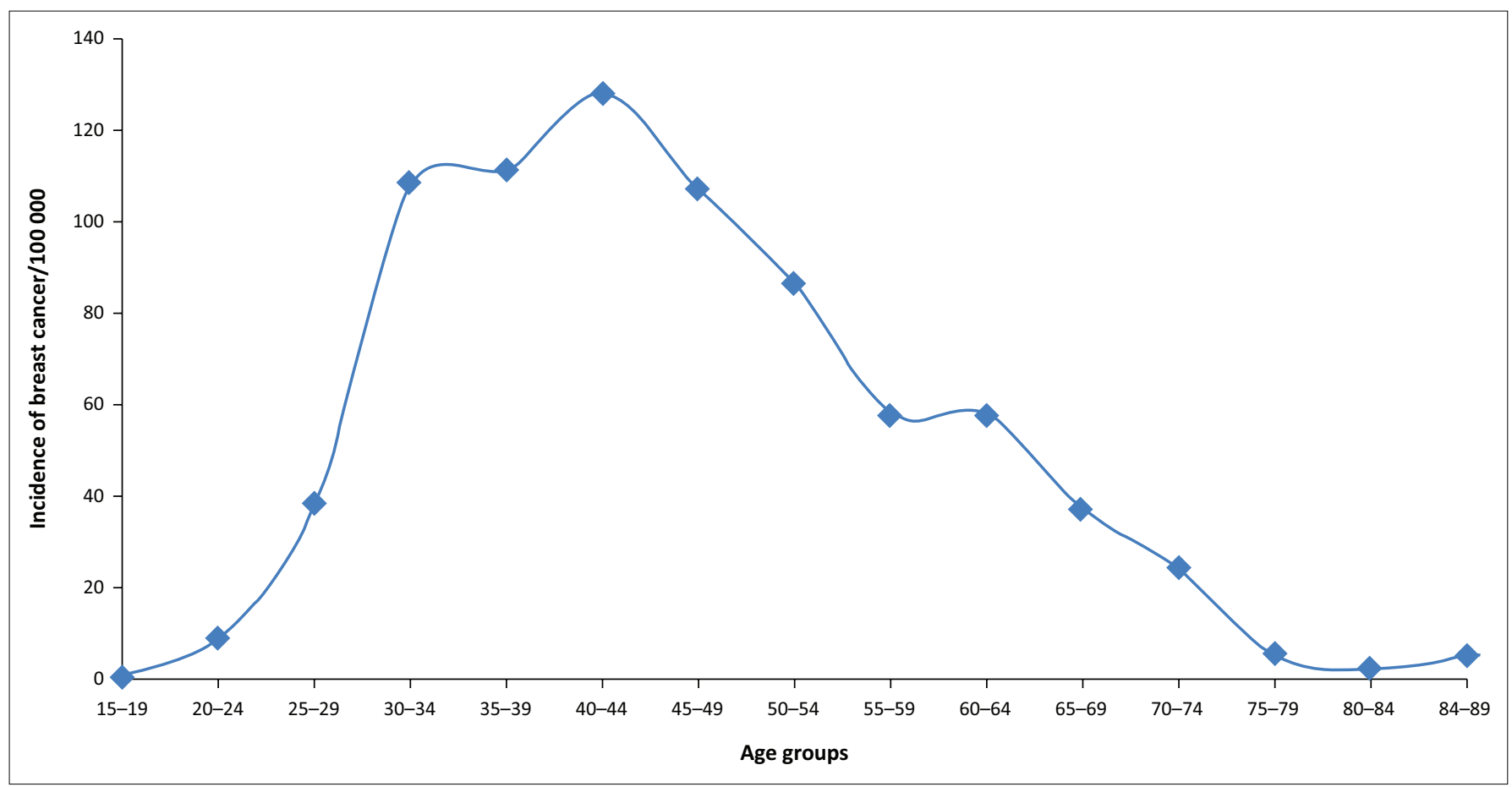

Source: Authors data compilation/creative works, 2018

FIGURE 1: Frequency of breast cancer by age groups.

TABLE 1: Age-specific rate for males and females.

\begin{tabular}{|c|c|c|c|c|c|c|c|c|c|c|c|c|c|c|c|c|c|c|c|}
\hline Year & $\begin{array}{c}0-4 \\
\text { years }\end{array}$ & $\begin{array}{c}5-9 \\
\text { years }\end{array}$ & $\begin{array}{l}0-14 \\
\text { ears } \\
\end{array}$ & $\begin{array}{l}15-19 \\
\text { years }\end{array}$ & $\begin{array}{l}20-24 \\
\text { years }\end{array}$ & $\begin{array}{l}25-29 \\
\text { years }\end{array}$ & $\begin{array}{l}30-34 \\
\text { years }\end{array}$ & $\begin{array}{c}35-39 \\
\text { years }\end{array}$ & $\begin{array}{l}40-44 \\
\text { years }\end{array}$ & & $\begin{array}{l}50-54 \\
\text { years }\end{array}$ & $\begin{array}{c}55-59 \\
\text { years }\end{array}$ & & & & & & $\begin{array}{c}85+ \\
\text { years }\end{array}$ & Overall \\
\hline & 000 & & & & & & & & & & & & & & & & 000 & 0.00 & \\
\hline & (10 & & & & & & & & & & & & & 42.17 & 18.02 & & 年 & 0.00 & \\
\hline 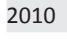 & 0.00 & & & & & & 20.0 & & & & 10.00 & & נינ. & 54.49 & & 32.07 & & 27.38 & 322.08 \\
\hline 11 & 0.00 & 0.00 & 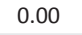 & 1.10 & .00 & 2.07 & .40 & 11.65 & 13.68 & 20.53 & 21 & .00 & 21.00 & 52.80 & 0.00 & 0.00 & 0.00 & 0.00 & 145.33 \\
\hline 12 & 0.00 & 0.00 & 0.00 & 0.00 & 0.00 & 1.34 & 11.95 & 17.56 & 16.57 & 17.68 & 33.10 & 10.96 & 63.36 & 38.37 & 32.78 & 30.11 & 27.24 & 25.72 & 326.74 \\
\hline 13 & 0.00 & 0.00 & 0.00 & 0.00 & 0.62 & 5.18 & 16.92 & 21.88 & 32.12 & 27.84 & 32.08 & 74.35 & 54.58 & 49.58 & 0.00 & 0.00 & 0.00 & 0.00 & 315.15 \\
\hline 015 & 0.00 & 0.00 & 0.00 & 0.00 & 0.59 & 1.83 & 10.03 & 14.84 & 21.11 & 34.18 & 38.33 & 49.87 & 51.24 & 69.82 & 59.66 & 0.00 & 0.00 & 23.40 & 374.89 \\
\hline 016 & 0.00 & 0.00 & 0.00 & 0.00 & 0.00 & 0.00 & 8.91 & 12.17 & 35.06 & 35.07 & 37.15 & 28.99 & 55.86 & 45.10 & 72.27 & 26.55 & 0.00 & 22.67 & 379.80 \\
\hline 2017 & 0.00 & 0.00 & 0.00 & 0.00 & 1.10 & 4.00 & 10.99 & 23.58 & 45.30 & 49.08 & 38.56 & 56.19 & 66.16 & 54.64 & 56.01 & 51.45 & 0.00 & 21.97 & 479.02 \\
\hline & 0.00 & 0.00 & 0.00 & 0.78 & 5.81 & 24.56 & 96.02 & 133.65 & 199.18 & 221.78 & 244.71 & 300.09 & 386.78 & 455.02 & 374.48 & 140.17 & 52.82 & 121.13 & 2756.97 \\
\hline
\end{tabular}

TABLE 2: Age-adjusted rate for males and females.

\begin{tabular}{|c|c|c|c|c|c|c|c|c|c|c|c|c|c|c|c|c|c|c|c|}
\hline $\begin{array}{l}\text { Age per } \\
\text { year }\end{array}$ & $\begin{array}{c}0-4 \\
\text { years }\end{array}$ & $\begin{array}{c}5-9 \\
\text { years }\end{array}$ & $\begin{array}{l}10-14 \\
\text { years }\end{array}$ & $\begin{array}{l}15-19 \\
\text { years }\end{array}$ & $\begin{array}{l}20-24 \\
\text { years }\end{array}$ & $\begin{array}{l}25-29 \\
\text { years }\end{array}$ & $\begin{array}{l}30-34 \\
\text { years }\end{array}$ & $\begin{array}{l}35-39 \\
\text { years }\end{array}$ & $\begin{array}{l}40-44 \\
\text { years }\end{array}$ & $\begin{array}{l}45-49 \\
\text { years }\end{array}$ & $\begin{array}{l}50-54 \\
\text { years }\end{array}$ & $\begin{array}{l}55-59 \\
\text { years }\end{array}$ & $\begin{array}{l}60-64 \\
\text { years }\end{array}$ & $\begin{array}{l}65-69 \\
\text { years }\end{array}$ & $\begin{array}{l}70-74 \\
\text { years }\end{array}$ & $\begin{array}{l}75-79 \\
\text { years }\end{array}$ & $\begin{array}{l}80-84 \\
\text { years }\end{array}$ & $\begin{array}{c}85+ \\
\text { years }\end{array}$ & Overall \\
\hline 2008 & 0.00 & 0.00 & 0.00 & 0.00 & 0.12 & 0.06 & 0.16 & 0.41 & 0.12 & 0.15 & 0.55 & 0.57 & 0.89 & 0.00 & 0.82 & 0.00 & 0.00 & 0.00 & 3.85 \\
\hline 2009 & 0.00 & 0.00 & 0.00 & 0.00 & 0.00 & 0.00 & 0.38 & 0.79 & 0.72 & 0.29 & 0.71 & 0.27 & 0.00 & 1.25 & 0.40 & 0.00 & 0.00 & 0.00 & 4.82 \\
\hline 2010 & 0.00 & 0.00 & 0.00 & 0.00 & 0.11 & 0.40 & 1.04 & 0.67 & 1.28 & 1.56 & 0.86 & 1.59 & 1.12 & 1.61 & 1.16 & 0.49 & 0.00 & 0.17 & 12.06 \\
\hline 2011 & 0.00 & 0.00 & 0.00 & 0.07 & 0.05 & 0.16 & 0.72 & 0.83 & 0.90 & 1.24 & 0.33 & 0.26 & 0.81 & 1.56 & 0.00 & 0.00 & 0.00 & 0.00 & 6.95 \\
\hline 2012 & 0.00 & 0.00 & 0.00 & 0.00 & 0.00 & 0.11 & 0.91 & 1.26 & 1.09 & 1.07 & 1.78 & 0.50 & 2.36 & 1.14 & 0.72 & 0.46 & 0.25 & 0.16 & 11.79 \\
\hline 2013 & 0.00 & 0.00 & 0.00 & 0.00 & 0.05 & 0.41 & 1.29 & 1.56 & 2.12 & 1.68 & 1.72 & 3.38 & 2.03 & 1.47 & 0.00 & 0.00 & 0.00 & 0.00 & 15.72 \\
\hline 2014 & 0.00 & 0.00 & 0.00 & 0.00 & 0.00 & 0.35 & 0.53 & 0.42 & 0.21 & 0.25 & 1.06 & 0.94 & 0.74 & 1.42 & 1.02 & 0.00 & 0.23 & 0.00 & 7.16 \\
\hline 2015 & 0.00 & 0.00 & 0.00 & 0.00 & 0.05 & 0.14 & 0.76 & 1.06 & 1.39 & 2.06 & 2.06 & 2.27 & 1.91 & 2.07 & 1.32 & 0.00 & 0.00 & 0.15 & 15.24 \\
\hline 2016 & 0.00 & 0.00 & 0.00 & 0.00 & 0.00 & 0.00 & 0.68 & 0.87 & 2.31 & 2.12 & 1.99 & 1.32 & 2.08 & 1.33 & 1.60 & 0.40 & 0.00 & 0.14 & 14.85 \\
\hline 2017 & 0.00 & 0.00 & 0.00 & 0.00 & 0.09 & 0.32 & 0.84 & 1.69 & 2.99 & 2.96 & 2.07 & 2.56 & 2.46 & 1.62 & 1.24 & 0.78 & 0.00 & 0.14 & 19.74 \\
\hline otal & 0.00 & 0.00 & 0.00 & 0.07 & 0.48 & 1.95 & 7.31 & 9.56 & 13.13 & 13.40 & 13.14 & 13.65 & 14.39 & 13.47 & 8.28 & 2.13 & 0.48 & 0.76 & 112.18 \\
\hline
\end{tabular}

(8\%) were of the specified types, including papillary (49 cases), mucinous ( 7 cases) and medullary (6 cases).

Lobular carcinoma was next to ductal carcinomas with 11 cases $(1.4 \%)$, all of which were infiltrative. Malignant stromal tumours composed the least category of $5 / 777$ cases $(0.6 \%)$. They were made up of two cases each $(0.3 \%)$ of rhabdomyosarcoma and fibrosarcoma and one case $(0.1 \%)$ of malignant phylloides tumour. There is no significant disparity in the distribution of the morphologic types between males and females as both showed marked predominance of infiltrating ductal carcinoma NOS. 


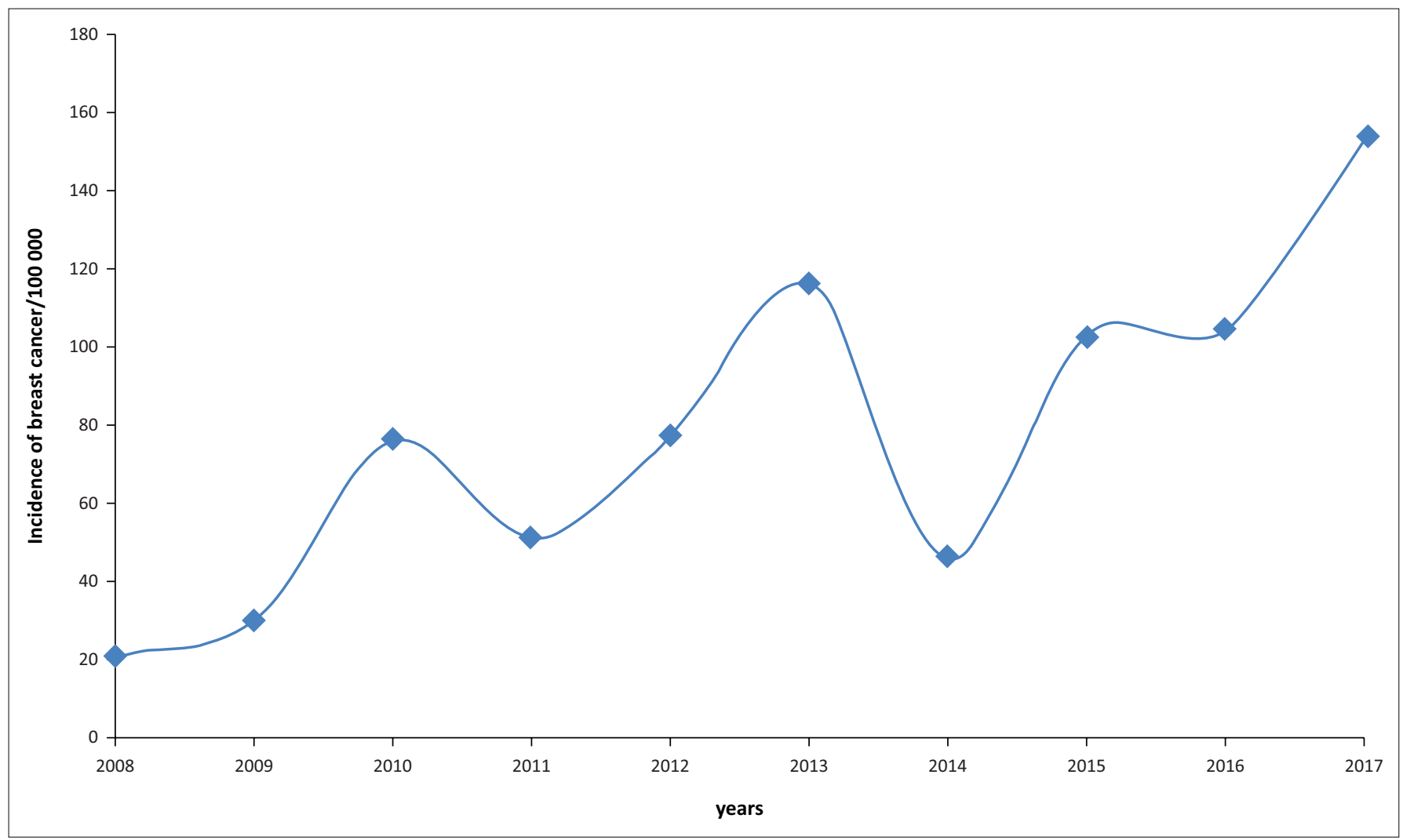

Source: Authors data compilation/creative works, 2018

FIGURE 2: Frequency of breast cancer from 2008 to 2017.

Grading shows predominance of well-differentiated carcinomas, with 408 cases (52.5\%) over poorly differentiated with 337 cases (43.3\%) and moderately differentiated carcinomas with 32 cases (4.1\%).

Histology of tissue biopsy and fine needle aspiration cytology were the bases of diagnoses in 693 cases (89.2\%) and 11 cases $(1.4 \%)$, respectively, while clinical examination only accounted for 66 cases (8.5\%). Death certificate review yielded seven cases $(0.9 \%)$.

\section{Discussion}

As BCA continues to attract research attention globally, this work provides the first population-based incidence estimates in Port Harcourt and environs. Attracting the intervention of donor agencies and even government's interests in appropriately allocating scarce resources towards the prevention, screening, diagnosis, treatment and palliative care for BCA patients as well as the monitoring of their effectiveness hinges on detailed information on its burden in our locality, which is what this work provides.

Breast cancer was the most frequently diagnosed cancer in PHCR - constituting $29 \%$ of all cancers and $49.7 \%$ of female malignancies as well as $3 \%$ of male malignancies. This alludes to the heavy burden of BCA in our locality. Breast cancer is now the most common cancer worldwide with the incidence of 2.4 million cases as of $2015 .{ }^{1}$ The heterogeneity in the disease burden across countries is such that higher incidence levels are recorded in the developed, Western countries as opposed to the medium- and the low-income countries, to which Nigeria belongs. ${ }^{14}$ The highest rates of BCA are recorded in Western Europe and the United States and the lowest rates in Africa and Asia. ${ }^{15}$ In 2012, globally, the 1.7 million recorded new cases of BCA constituted $25 \%$ of female cancers, while in 2015, despite the acclaimed high rate of BCA in the United States, it constituted only $29 \%$ of female cancers. ${ }^{16}$ Also, in Europe, BCA constituted 464000 cases out of the 3.45 million incident cases, which is $13.4 \%$. A comparison of these proportions with ours suggests high rate of BCA in our environment. Approximately one in every two cancer diagnoses among our women is BCA and with the annual ASR that ranged between 222 and 975/100 000 and the AAR that ranged between 8.8 and 42.4/100 000 (mean of $25.8 / 100$ 000), it is obvious that the burden of BCA among women in Port Harcourt and the environs demands an urgent intervention. This value is way beyond the GLOBOCAN 2012 estimate of BCA incidence in Africa which ranged from 27/100000 women in central Africa to $39 / 100000$ women in southern Africa. ${ }^{5}$ It is comparable to 43.9/100 000 reported for Greece. ${ }^{4,5}$ Addressing this high burden of BCA among our women is important because of its overriding positive health impact, which will reduce gender inequalities and project the role of women as societal and economic participants, as well as family caretakers. ${ }^{17}$ Studies have pointed out that the increasing rate of cancers in general and BCA in particular among the low- and middle-income countries like Nigeria is a reflection of the trends in the wealthier countries and the associated Westernised lifestyles 
of unhealthy diet, tobacco consumption, sedentary lifestyle and changing reproductive patterns that confer higher risk of BCA. ${ }^{18,19}$ In addition, the very high incidence of BCA in high-income countries reflects the use of BCA screening. ${ }^{20}$ Screening for BCA is uncommon in our local environment, the effect of which is under diagnosis, under representation and late-stage disease and poor prognosis. Therefore, public health measures aimed at developing and implementing BCA prevention strategies and awareness among our populace are strongly advocated.

The age range of the patients was 15-98 years, while the mean age was 45.9 years. The peak age group was 40-44 years in the females and 65-69 years in the males with the mean age of 45.5 and 53.5 years, respectively. Findings from this study compare well with the previous BCA studies in Nigeria, which indicate patients' wide age range of 14-96 years and low mean age that ranges between 42.7 and 50 years and peak age group of $36-45$ years. ${ }^{21,22,23}$ The same relatively early age at diagnosis is reported across Africa in a continental review study, which showed that $81 \%$ of African BCA women are aged 30-59 years. ${ }^{20}$ Indeed, the diversity of BCA with age, ethnicity and socio-economic development is pronounced. For example, among women of reproductive age in developing countries, the likelihood of developing BCA is twice compared with their counterparts from the developed countries, and more than two-thirds of cases in developed countries occur in women of age 50 years and above unlike those of the developing nations. ${ }^{24}$ This is further attested to in the findings of this work, where the mean age is comparatively much lower than the figures in the United States and Europe. Patients younger than 45 years constituted $54.4 \%$, while those 45 years and older constituted $45.6 \%$. The proportion of young patients here is way above what has been reported in other local and international studies. For instance, a study in Ibadan (south-west Nigeria) showed that the proportion of women aged 40 years and younger having BCA was $29 \%$, which is still way higher than the $6 \%$ and $9.6 \%$ reported in Australia and South Korea, respectively. ${ }^{25,26,27}$ Also, in the United States, only $22 \%$ of cases are diagnosed before age 50 years among women having BCA. ${ }^{28}$ Researchers have shown that women who develop BCA before their fifth decade of life usually have more aggressive disease and poorer prognosis..$^{29,30}$

Although the annual frequency trend is undulating, there is an overall increase in the trend from the 21 cases recorded in 2008 to 153 cases recorded in 2017. The factors that could account for the undulating trend include intermittent interruption in the health sector activities occasioned by strike actions by different workers' unions. This would result in a drop in the recorded tertiary hospital cases, as patients seek alternative treatments, often out of the state for the majority who may not afford the relatively expensive private practitioners fares and inconsistent availability of field staff for data gathering. However, despite these shortcomings, the leap in the recorded cases may also reflect improvement in the reporting efficiency of the field data gathering staff of our registry as well as management support. This noted increasing trend is consistent with the growing cancer burden in different geographic regions of the world, which has been generally ascribed to growing and ageing global population, smoking, obesity and dietary patterns. ${ }^{31,32}$ The aforementioned factors are global, but among the factors that are likely at play in our environment are child bearing at late age, reduced parity, short period of breast feeding as well as early menarche, late menopause and alcohol consumption. It has been reported that for each year of delay in attaining menarche the risk of having BCA decreases by about 15\%, and for each year of delay of menopause it increases by about $3 \%$ and BCA risk increases by about $7 \%-12 \%$ per unit of alcohol per day. 33,34

The predominance of ductal carcinomas with up to $98 \%$ in this study is consistent with other Nigerian studies, which demonstrated ductal carcinoma prevalence in a range of $92 \%-98 \%{ }^{23,25,35}$ Infiltrating lobular carcinoma constituted only $1.4 \%$, which is far below the $10 \%-15 \%$ range reported for developed nations. ${ }^{36,37}$ Because lobular carcinoma has better prognosis, its decimal proportion in our population further adds to the mortality burden of BCA. ${ }^{38,39}$ Also, worthy of note is the finding of $0.7 \%$ rate of in situ carcinoma. This underscores the underutilisation of BCA screening programmes, especially mammography. Mammography screening can prevent BCA deaths by detecting cancer at an early stage when treatment is more effective. The unacceptability and unpopularity of mammography in our locality, therefore, significantly accounts for the reported high prevalence of late-stage cases and attendant high mortality rate in Nigeria. In contrast, developed countries with higher incidence of BCA have relatively low mortality because of early detection of cases aside from their good technological infrastructure and better trained manpower. ${ }^{15}$ Therefore, key among intervention measures would be to avail mammographic services at subsidised and affordable costs and increase awareness on its importance in the early identification of cases.

Well-differentiated carcinomas slightly predominated over poorly differentiated ones with $52.5 \%$ and $43.3 \%$, respectively. This finding is inconsistent with most reports from Nigeria and Africa, where poorly differentiated cancers predominate. This discrepancy could be because of errors - both at intra-observer and inter-observer levels. In addition, the inconsistency in the use of a specific grading system by pathologists could result in difficulty in the harmonisation of the heterogeneous grading systems in the course of data abstraction by field registrars. A change of the simple grading system provided in the CanReg 4 data entry and storage software (which we used in this study) to any of the more objective and reliable grading systems like the Scarff-BloomRichardson or the Nottingham grading systems would improve the objectivity of reported BCA grades in Nigeria's cancer registry system. 


\section{Limitations}

Patronage of unorthodox and unregistered treatment centres like religious and herbal homes, and even nonpresentation of some cases on account of poverty and nonaffordability of hospital treatment, makes under-reportage likely. Also, the inconsistent documentation of patient information in the various case notification centres makes missing out on some cases possible, and finally the ad hoc basis of registry staff deployment and irregular logistic support to the registry makes consistency of data gathering porous.

\section{Conclusion}

The burden of BCA is heavy in Port Harcourt, and mean age is lower than the figures of developed nations. Instituting measures that will entrench prevention, screening, timely diagnosis and improved treatment is imperative.

\section{Acknowledgements}

The authors thank the Institute of Human Virology (IHVN), Abuja, and the Cancer Unit of the Federal Ministry of Health, Abuja, Nigeria, for their technical support and trainings. They would also like to thank Profs. A.C. Ojule, C. Mato and H.A. Ugboma and Dr C. Tobin-West for their administrative support to the registry at different periods and all the ad hoc staff who had been part of the struggle to keep the registry ongoing, including resident doctors in Anatomical Pathology Department (Drs Chukwudi Onwumelu and Solomon Obioha); laboratory scientists (Mr Dee Emmanuel and Martha Akpanumoh); other staff (Matron Solomon (late), Prince Ujons, Caroline and Mrs Gift Oletu); Dr Tope Osagbemiro and Uru Ugada for their statistical analysis support; Dr K.C. Okereke and his team of experts at the National Population Commission and National Bureau of Statistics for their population projection which was part of the study.

\section{Competing interests}

The authors declare that they have no financial or personal relationships that may have inappropriately influenced them in writing this article.

\section{Authors' contributions}

C.C.O. designed the study and wrote the manuscript. E.K.A. read and contributed to the discussion.

\section{Funding}

This research received no specific grant from any funding agency in the public, commercial or not-for-profit sectors.

\section{Data availability statement}

Data sharing is not applicable to this article as no new data were created or analysed in this study.

\section{Disclaimer}

The views and opinions expressed in this article are those of the authors and do not necessarily reflect the official policy or position of any affiliated agency of the authors.

\section{References}

1. Fitzmaurice C, Allen C, Barber RM, et al. Global, regional, and national cance incidence, mortality, years of life lost, years lived with disability, and disability adjusted life-years for 32 cancer groups, 1990 to 2015: A systematic analysis for the global burden of disease study. JAMA Oncol. 2017;3(4):524-548. https://doi. org/10.1001/jamaoncol.2016.5688

2. Porter P. 'Westernizing' women's risks? Breast cancer in lower-income countries. N Engl J Med. 2008;358(3):213-216. https://doi.org/10.1056/NEJMp0708307

3. Parkin D, Ferlay J, Hamdi-Chérif $M$, et al. Cancer in Africa: Epidemiology and prevention. IARC Sci Publ. 2003;153:1-414.

4. Zeng $\mathrm{H}$, Zheng R, Zhang S, Zou X, Chen W. Female breast cancer statistics of 2010 in China: Estimates based on data from 145 population-based cancer registries. J Thorac Dis. 2014;6(5):466-470.

5. Ferlay J, Soerjomataram I, Dikshit R, et al. Cancer incidence and mortality worldwide: Sources, methods and major patterns in GLOBOCAN 2012. Int Cancer. 2015;136(5):E359-E386. https://doi.org/10.1002/ijc.29210

6. Ferlay J, Shin HR, Bray F, Forman D, Mathers C, Parkin DM. Estimates of worldwide burden of cancer in 2008: GLOBOCAN 2008. Int J Cancer. 2010;127:2893-2917. https://doi.org/10.1002/ijc.25516

7. Brinton LA, Figueroa JD, Awuah B, et al. Breast cancer in Sub-Saharan Africa: Opportunities for prevention. Breast Cancer Res Treat. 2014;144(3):467-478. https://doi.org/10.1007/s10549-014-2868-z

8. Jedy-Agba E, McCormack V, Adebamowo C, Dos-Santos-Silva I. Stage at diagnosis of breast cancer in sub-Saharan Africa: A systematic review and meta-analysis. Lancet Global Health. 2016;4(12):e923-e935. https://doi.org/10.1016/S2214109X(16)30259-5

9. Pace LE, Shulman LN. Breast cancer in sub-Saharan Africa: Challenges and opportunities to reduce mortality. Oncologist. 2016;21(6):739-744. https://doi. org/10.1634/theoncologist.2015-0429.

10. Al-Haddad BJS, Jedy-Agba E, Oga E, et al. Comparability, diagnostic validity and completeness of Nigerian cancer registries. Cancer Epidemiol. 2015;39(3):456-464. https://doi.org/10.1016/j.canep.2015.03.010

11. Parkin DM, Wabinga $\mathrm{H}$, Nambooze S. Completeness in an African cancer registry Cancer Causes Control. 2001;12(2):147-152. https://doi.org/10.1023/A:100896 6225984

12. Percy CL, Van Holten V, Muir CS. International classification of diseases for oncology. 2nd ed. Geneva: World Health Organization; 1990.

13. Ahmad OB, Boschi-Pinto C, Lopez AD, Murray CJL, Lozano R, Inoue M. Age standardization of rates: A new WHO standard. GPE Discussion Paper Series: No.31 EIP/GPE/EBD. Geneva: World Health Organization; 2001; p. 9(10).

14. Bellanger $\mathrm{M}$, Zeinomar $\mathrm{N}$, Tehranifar $\mathrm{P}$, Beth Terry $\mathrm{M}$. Are global breast cancer incidence and mortality patterns related to country-specific economic incidence and mortality patterns related to country-specific economic
development and prevention strategies? J Glob Oncol. 2018;4(4):1-16. https:// development and prevention st
doi.org/10.1200/JGO.17.00207

15. Torre LA, Siegel RL, Ward EM, Jemal A. Global cancer incidence and mortality rates and trends - An Update. Cancer Epidemiol Biomarkers Prev. 2016;25(1):16-27. https://doi.org/10.1158/1055-9965.EPI-15-0578

16. Ferlay J, Soerjomataram I, Dikshit R, et al. Cancer incidence and mortality worldwide: Sources, methods and major patterns in GLOBOCAN 2012. Int I Cancer. 2015;136(5):E359-E386.

17. World Health Organization. Women and health: Today's evidence, tomorrow's agenda. Geneva: World Health Organization; 2009.

18. Bray F, Jemal A, Torre LA, Forman D, Vineis P. Long-term realism and costeffectiveness: Primary prevention in combatting cancer and associated inequalities worldwide. J Natl Cancer Inst. 2015;107(12):273-284. https://doi.org/10.1093/ jnci/djv273

19. Ginsburg O, Bray F, Coleman MP, et al. The global burden of women's cancers: A grand challenge in global health. Lancet. 2017;389(10071):847-860. https:// doi.org/10.1016/S0140-6736(16)31392-7

20. Adeloye D, Sowunmi OY, Jacobs W, et al. Estimating the incidence of breast cance in Africa: A systematic review and meta-analysis. J Glob Health. 2018;8(1):010419. https://doi.org/10.7189/jogh.08.010419

21. Ikpatt OF, Kuopio T, Ndoma-Egba R, Collan Y. Breast cancer in Nigeria and Finland: Epidemiological, clinical and histological comparison. Anticancer Res. 2002;22(5): 3005-3012.

22. Adetifa FA, Ojikutu RK. Prevalence and trends in breast cancer in Lagos State, Nigeria. Afr Res Rev. 2009;3(5):1-15. https://doi.org/10.4314/afrrev.v3i5.51137

23. Ukah C, Emegoakor C, Anyiam D, et al. The immunohistochemical profile of breast cancer in indigenous women of Southeast Nigeria. Ann Med Health Sci Res. 2017;7(7):83-87.

24. Forouzanfar MH, Foreman KJ, Delossantos AM, et al. Breast and cervical cancer in 187 countries between 1980 and 2010: A systematic analysis. Lancet. 2011;378(9801):1461-1484. https://doi.org/10.1016/S0140-6736(11)61351-2 
25. Ntekim A, Nufu FT, Campbell OB. Breast cancer in young women in Ibadan, Nigeria. Afr Health Sci. 2009;9(4):242-246.

26. Bech AG, Australian Institute of Health and Welfare. Breast cancer in Australia: An overview. Canberra: Australian Institute of Health and Welfare; 2012, p. 1-5.

27. Kim JK, Kwak BS, Lee JS, et al. Do very young korean breast cancer patients have worse outcomes? Ann Surg Oncol. 2007;14(12):3385-3391. https://doi. org/10.1245/s10434-006-9345-9

28. DeSantis C, Siegel R, Jemal A. Breast cancer facts \& figures, 2013-2014. Atlanta: American Cancer Society, Inc., 2013; p. 40.

29. Elston CW, Ellis IO. Pathological prognostic factors in breast cancer. I. The value of histological grade in breast cancer: Experience from a large study with long-term follow-up. Histopathology. 1991;19;403-410.

30. Devi KR, Kuruvila S, Musa MM. Pathological prognostic factors in breast carcinoma. Saudi Med J. 2000;21(4):372-375.

31. Lozano R, Naghavi M, Foreman K, et al. Global and regional mortality from 235 causes of death for 20 age groups in 1990 and 2010: A systematic analysis for the
Global Burden of Disease Study 2010. Lancet. 2012;380(9859):2095-2128. https://doi.org/10.1016/S0140-6736(12)61728-0

32. Murray CJ, Lopez AD. Mortality by cause for eight regions of the world: Globa burden of disease study. Lancet. 1997;349 (9061):1269-1276. https://doi.org/ burden of disease study. Lancet.
33. Allen NE, Beral V, Casabonne D, et al. Moderate alcohol intake and cancer incidence in women. J Natl Cancer Inst. 2009;101(5):296-305. https://doi.org/ $10.1093 /$ jnci/djn514

34. Stewart BW, Wild CP, editors. World cancer report 2014. Lyon: International Agency for Research on Cancer; 2014.

35. Agbo PS, Khalid A, Oboirien M. Clinical presentation, prevalence and management of breast cancer in Sokoto, Nigeria. J Womens Health Care. 2014;3:149. https:// doi.org/10.4172/2167-0420.1000149

36. Portschy PR, Marmor S, Nzara R, Virnig BA, Tuttle TM. Trends in incidence and management of lobular carcinoma in situ: A population-based analysis. Ann Surg Oncol. 2013;20(10):3240-3246. https://doi.org/10.1245/s10434-013-3121-4

37. Louwman MW, Vriezen M, Van Beek MW, et al. Uncommon breast tumors in perspective: Incidence: Treatment and survival in the Netherlands. Int J Cancer. 2007;121(1):127-135. https://doi.org/10.1002/ijc.22625

38. Biglia N, Maggiorotto F, Liberale V, et al. Clinical pathologic features: Long termoutcome and surgical treatment in a large series of patients with invasive lobular outcome and surgical treatment in a large series of patients with invasive lobular
carcinoma (ILC) and invasive ductal carcinoma (IDC). Eur J Surg Oncol. carcinoma (ILC) and invasive ductal carcinoma (IDC). Eur
2013;39(5):455-460. https://doi.org/10.1016/j.ejso.2013.02.007

39. Korhonen T, Kuukasjarvi $\mathrm{H}$, Huhtala EL, et al. The impact of lobular and ducta breast cancer histology on the metastatic behavior and long term survival of
breast cancer patients. Breast. 2013;22(6):1119-1124. https://doi.org/10.1016/j. breast cancer patients 